\title{
Working and Educated Women: Culprits of a European Kinder-Crisis?
}

\author{
Elizabeth A. DiCioccio ${ }^{\mathrm{a}}$ and Phanindra V. Wunnava ${ }^{\mathrm{b}}$ \\ ${ }^{a}$ Merrill Lynch Private Equity Group, Merrill Lynch Financial Centre, London EC1A 1HQ, UK \\ ${ }^{\mathrm{b}}$ Economics Department, Middlebury College, Warner Hall 502F, Middlebury, Vermont 05753, USA; \\ and IZA (BONN, GERMANY) \\ E-mail: wunnava@middlebury.edu
}

Recently, many industrialized countries have posted fertility rates below the replacement rate, generating concern that populations in these countries are rapidly declining. Low fertility rates are often believed to be the result of greater opportunities for women in the workforce and in higher education. Past studies have reinforced this belief by showing that a negative correlation often exists between female labor force participation and fertility and female higher education attainment and fertility. This study uses crosssectional time-series data for 13 European Union (EU) countries covering the years 1990-2003 to test whether this negative relationship between workforce participation and fertility still exists. The findings of this study show that neither increased female education nor increased labor force participation were significant in determining fertility. However, other social and labor market trends, such as the prevalence of part-time employment, unemployment rate, age at marriage, and contraceptive use, were found to be significant.

Eastern Economic Journal (2008) 34, 213-222. doi:10.1057/palgrave.eej.9050029

Keywords: childbearing; child care; fertility; lafor force participation

JEL: J13; J21; J33

\section{INTRODUCTION}

In recent decades, a growing number of developed countries have experienced dwindling fertility rates. Decreasing fertility rates in such countries can potentially be attributed to the evolution of greater opportunities for women in industrialized nations. It is conceivable that the responsibilities associated with childbearing have become increasingly difficult to manage as the opportunities in higher education and careers have grown for women. As the development of opportunities for women is among the greatest indicator of social progress for developed countries in recent years, such opportunities should continue to be strongly promoted. However, if this social progress is significantly contributing to lower fertility rates, countries with shrinking populations may also find these trends worrisome.

Hence, the aim of the empirical testing in this study is to determine whether female labor force participation is a principal culprit of lower fertility rates in European Union (EU) countries. Previous studies that have tested this relationship have used data that extended back at least into the 1970s [Becker and Lewis 1973; Willis 1973; Engelhardt et al. 2001; Del Boca 2003]. When using this time frame, it is more likely that workforce participation will negatively influence fertility decisions, as in this early time period, government and firm fertility programs were less common. However, two recent longitudinal studies ${ }^{1}$ based on a sample of developed countries by Ahn and Mira [2002] covering 1970-1995, and by Adsera [2004] covering 
1960-1997 have already detected a changing relationship between fertility and female labor force participation rates. Specifically, both these studies found that since the late 1980s there exists a positive relationship between these two measures, as more targeted programs have since been developed to mitigate the effects of childbearing. Hence, one of the main objectives of this study is to investigate whether these positive trends could still be detected by extending the sample years to include the current millennium and also identify other significant variables that may impact European fertility. Accordingly, such an investigation will provide critical information to the respective governments, enabling them to design appropriate policies to alleviate lower fertility among European women.

\section{BACKGROUND}

Past studies have cited several labor market conditions, as well as various social conditions and social programs as determinants of fertility decisions in industrialized nations. The following section addresses each of these previously identified determinants.

\section{Labor market conditions}

A wealth of previous literature suggests that fertility patterns are affected by labor market conditions within a country. ${ }^{2}$ Female workforce participation has often been cited as a potential determinant in fertility decisions. The availability of part-time employment opportunities for females is also believed to play a role in fertility decisions, as it allows women to balance familial and work responsibilities. Overall unemployment rate, serving as an indicator of labor market stability, may also affect a country's fertility patterns.

\section{Female labor force participation}

Early econometric studies find that increased female participation in the labor market significantly contributes to decreasing fertility rates in developed countries [Becker and Lewis 1973; Willis 1973], and further fertility could be countercyclical [Butz and Ward 1979]. Given that an increasing number of European women are participating in the labor force, increased labor force participation may logically explain the lower fertility rates. However, a more recent analysis suggests that, beginning in the mid-1980s, the traditionally strong negative relationship between female participation rate and fertility began to break down in several Northern European countries [Del Boca 2003]. Such North European countries began to post both increasing fertility rates and increasing female participation rates. This may be due to the fact that Northern European countries had implemented fertility programs that sufficiently assisted working mothers. However, in Mediterranean countries, the negative correlation between female participation rate and fertility rate continued to persist throughout the early 1990s [Engelhardt et al. 2001; Righi 2003]. These more recent studies have shown that the current relationship between female labor force participation and fertility rate is somewhat ambiguous and has been undergoing constant change in recent years.

\section{Female part-time employment}

Whereas the current relationship between female labor force participation and fertility rate remains unclear, recent studies have shown that there is a positive 
correlation between the proportion of women with part-time jobs and the overall fertility rate in a country [Di Tommaso 1999; Del Boca 2003]. Women who face more flexible labor conditions tend to have more time available to dedicate to the responsibilities of childbearing. The greater availability of part-time job opportunities within a country reduces the opportunity cost of having children, as mothers will be less likely to have to give up their jobs to raise their children. In a carefully conducted empirical study based on provincial-level Italian panel data, Del Boca [2002] documents that availability of child care and part-time work increase both the probability of working and having a child.

\section{Unemployment rate}

High unemployment within a country has been identified as having a negative relationship with fertility rates [Righi 2003]. In countries where the unemployment rate is high, women will be less likely to leave the labor market, knowing that it may be more difficult to reenter later due to the scarcity of jobs [Del Boca 2003]. Additionally, when there is greater insecurity in the labor market, parents may be more reluctant to have children because of the fear of not having enough income to support their potential children [Del Bono 2002]. In a recent paper, Adsera [2006], using the Spanish Fertility Surveys of 1985 and 1999, showed that women in their mid-20s facing a tight labor market and worsening economic conditions (i.e., high unemployment) tend to restrict their fertility ${ }^{3}$ below their ideal level, but this phenomenon seems to be much weaker if they were employed in a stable public sector job.

\section{Social trends}

In addition to labor market conditions, general social trends and conditions may indirectly or directly affect fertility patterns. Higher female tertiary education attainment and older age at marriage are trends that may be prompted by advanced opportunities for woman and are often associated with lower fertility rates. Additionally, the availability and social acceptance of contraceptives may contribute to lower fertility.

\section{Female tertiary education attainment}

In recent years, a far greater percentage of women in developed countries have attained tertiary education [Human Development Report]. Higher education for females is generally associated with lower fertility rates, as high educational achievement leads to greater employment opportunities [Rindfuss et al. 1996; d'Addio and d'Ercole 2005]. Additionally, because the attainment of higher education requires considerable time investment, higher education tends to increase the age of women at childbirth [d'Addio and d'Ercole 2005]. An increase in age at childbirth contributes to lower fertility, as it reduces the number of years during which a woman can bear children.

\section{Marital trends}

Age at marriage has been found to be inversely related to fertility rate [d'Addio and d'Ercole 2005]. As women marry at an older age, they will tend to have children at a later age, which will reduce the amount of years available during which a woman can give birth. Age at marriage may be affected by female education level, as the age at 
marriage may be delayed due to additional years of schooling. Alternatively, age at marriage may be determined by general social trends or attitudes that are unrelated to educational achievement.

In addition to the age at which marriage occurs, marital status itself has been shown to contribute to fertility patterns. Countries that have a higher proportion of births occurring outside of wedlock have also been shown to have higher fertility rates [d'Addio and d'Ercole 2005]. Conversely, countries that have higher divorce rates have been shown to post lower fertility rates, as instable family conditions are likely to impede the decision to raise a family [d'Addio and d'Ercole 2005].

\section{Contraceptive use}

In their analysis of 13 countries in North America, Europe, and Asia, Marston and Cleland [2003] find that increased contraceptive use contributes to lower abortion rates in countries where fertility rates were constant. However, in countries whose fertility rates were falling, the effect of contraceptives ${ }^{4}$ on abortion was ambiguous. Therefore, the overall effect of contraceptives on fertility is unclear.

\section{Social programs}

In 1992, the European Commission passed a pregnancy directive, stating that all member countries of the EU must provide a minimum of a 14-week paid maternity leave. However, while some countries provide only the minimum 14-week program (Belgium, Germany, Portugal), other countries provide substantially more generous maternity leave programs. The United Kingdom (whose maternity leave length was increased from 18 to 26 weeks in 2003), Italy (20 weeks), Denmark (18 weeks), and Finland (18 weeks) offer the longest paid maternity leave programs. Rønsen [1999] and Neyer [2003] find that longer maternity leaves significantly impact a woman's decision to give birth to a child. In her study of parental leave policies in Scandinavia, Rønsen [1999] finds that countries with longer maternity leave programs have significantly higher fertility rates than countries with shorter maternity leave policies. Neyer [2003], using a sample of Western European countries, similarly finds that maternity leave programs ${ }^{5}$ significantly reduce the burdens associated with work for women.

\section{METHODOLOGY AND DATA}

This study seeks to empirically test the effect of female labor force participation and advanced female educational opportunities on fertility rate. If increased female participation in higher education and in the workforce does, in fact, strongly contribute to lower fertility rates, then these results may be a calling to European governments to implement or improve upon existing maternity programs to assist working mothers with the responsibilities of childbearing. However, if advanced opportunities for females do not have an effect on fertility decisions, it may be concluded that government and firm programs have already sufficiently lowered the burden of having children and focus should be on other relevant factors in designing appropriate policies. Accordingly, this study uses time-series cross-sectional data from 13 of the original 15 EU countries (Ireland and Luxembourg have been excluded because of the unavailability of a complete data set) and time-series data 
from 1990 to 2003. The final empirical model employed ${ }^{6}$ is as follows:

$$
\begin{aligned}
& F E R_{i, t}=\alpha_{0}+\alpha_{1} \stackrel{(-)}{E M}_{i, t}+\alpha_{2} P \stackrel{(+)}{A R T T_{i, t}} \\
& +\alpha_{3} \stackrel{(-)}{N E M P}_{i, t}+\alpha_{4} \stackrel{(-)}{E R}^{R} T_{i, t}+\alpha_{5} \stackrel{(-)}{M A} R_{i, t} \\
& +\alpha_{6} \text { OUTS }_{i, t}+\alpha_{7} \stackrel{(-)}{D I}_{i, t}+\alpha_{8} \text { CON }_{i, t} \\
& +\alpha_{9} S \stackrel{(+)}{O C}+\alpha_{10} M \stackrel{(+)}{A T E R} R_{i, t}+\varepsilon_{i, t}
\end{aligned}
$$

where $I=1,2, \ldots, 13$ (i.e., 13 EU countries) and $t=1990,1991, \ldots, 2003$ (i.e., 14 years). The dependent variable used, FER, measures the annual fertility rate of each European country used. Fertility rate is defined as the mean number of live children born to a woman during her lifetime. Data for fertility rates are obtained from the European Commission's Eurostat statistical database.

FEMP is defined as the female participation rate in the labor force as a percentage of the total female population over 15 years of age. Traditionally, female participation has had a negative effect on fertility rate in Europe, as working women face difficulties in balancing both work and family responsibilities. Data for participation rate are obtained from Eurostat.

An explanatory variable for part-time work conducted by females, PARTT, is included in the model to capture the effects that part-time work opportunities have on fertility rate. Female part-time employment is defined as the portion of working females who work fewer than $35 \mathrm{~h}$ per week. Whereas the overall effect of total female employment may be ambiguous, there is an expected positive correlation between part-time employment and fertility. Data for female part-time participation rate are obtained from Eurostat.

The explanatory variable, UNEMP, is included to control for the effect of overall labor market stability on fertility decisions. Unemployment rate represent the portion of male and female workers unemployed as a percentage of the total labor force. There is an expected negative correlation between unemployment rate and fertility rate, as unemployment generates economic instability, which hinders fertility decisions. Data for unemployment rates were obtained from the Human Development Report.

An explanatory variable for female attainment of tertiary education (TERT) is used in the econometric model to test for the effects of higher educational opportunities for women on fertility trends. Female tertiary education data represent female tertiary education attainment as a percentage of male tertiary education attainment. The attainment of tertiary education typically leads to greater career opportunities, which would have a negative overall effect on fertility rate. Female tertiary education rate data were taken from the Human Development Report.

$M A R$ refers to the median age at which women in each European country marry. A higher median age at marriage would predict a lower fertility rate, as fewer years would be available during which women can give birth to children. Therefore, there is an expected negative correlation between median marriage age and fertility rate in each country. Data for the median age at marriage are obtained from Eurostat.

Explanatory variables for birthrate outside of wedlock (OUTS), divorce rate $(D I V)$, and contraceptive use $(C O N)$ are included to control for the effects that social conditions on a country may have on fertility rate. The birthrate outside of 
wedlock represents the portion of children born to unmarried mothers. The correlation between the outside of wedlock birthrate and fertility is expected to be positive. Divorce rate is defined as the proportion of divorces per year as a percentage of the total population. Increased contraceptive use in a country is expected to negatively contribute to overall fertility rate. Data for contraceptive use indicate the percentage of adults who regularly report using any type of contraceptive. Data for births outside of wedlock, divorce rate, and contraceptive use were obtained from the Human Development Report.

The explanatory variable $S O C$ is included to control for the amount of government spending on maternity and family-related programs in each country. As the amount of spending on programs increases, the fertility rate in each country is predicted to increase. Data on maternity-relative expenditures were taken from Eurostat.

A variable for the length of government-mandated maternity leave program (MATER) is included to control for the effect that maternity leave has on a country's fertility pattern. Maternity leave is defined as the number of paid weeks a woman can take off from work. This variable is expected to have a positive effect on fertility rate; as the number of weeks is increased, the burden of balancing a child and work is expected to decrease. Information pertaining to the length of maternity leave has been gathered from websites of individual countries.

\section{EMPIRICAL ANALYSIS}

The results of a Hausman [1978] test of random vs fixed effects determined that a fixed effects specification is preferred to random effects. ${ }^{7}$ The fixed effects specification allows us to capture differences that may be present between individual countries included in the sample. Since pooled cross-sectional time-series data are used in this econometric model, there is the risk that the data suffer from autocorrelation problems. After correcting for autocorrelation, the revised econometric model yields the results reported in Table 1.

The coefficient estimators for unemployment rate (UNEMP) and maternityrelated expenditures $(S O C)$ are both significant at the $\alpha=0.01$ level. Female parttime employment participation rate $(P A R T T)$ and contraceptive prevalence rate $(C O N)$ both have coefficient estimators that are significant at the $\alpha=0.05$ level. The coefficient estimators for marriages that occur outside of wedlock (OUTS) and length of maternity leave (MATER) are significant at the 10 percent level.

Neither female labor force participation rate (FEMP) nor female tertiary attainment rate (TERT) is significant. ${ }^{8}$ This is contrary to our predictions, as increased career and educational opportunities for women are typically pinpointed as the primary culprit of a woman's decision to forgo having children. The fact that women's participation in the labor force and the attainment of higher education are not hindering fertility decisions suggests that equal opportunities in education and the workplace should continue to be promoted. ${ }^{9}$ Neither divorce rate $(D I V)$ nor median age at marriage $\left(M A R^{10}\right)$ was found to be significant. Additionally, an $F$-test was performed to test whether these four insignificant variables were jointly significant. However, the resulting test statistic was insignificant. ${ }^{11}$

The results identify that the length of maternity leave (MATER) and the amount of spending on social programs $(S O C)$ related to maternity both have a significantly positive impact on fertility decisions. For every percentage point increase in the 
Table 1 Auto correlation corrected pooled cross-section time-series estimates

\begin{tabular}{|c|c|c|c|c|c|c|}
\hline \multicolumn{3}{|c|}{$\begin{array}{l}\text { Dependent variable: FERTILITY } \\
\text { [Mean: } 1.542143 ; \text { s.d.: } 0.2174623 \text { ] }\end{array}$} & \multicolumn{2}{|c|}{ Fixed effects model } & \multicolumn{2}{|c|}{$\begin{array}{l}\text { Fixed effects model }+ \\
\text { time effects }\end{array}$} \\
\hline Variable name & Mean & Standard dev. & Est. coefficient & t-value & Est. coefficient & $t$-value \\
\hline FEMP & 42.67858 & 9.282548 & 0.0004689 & 0.57 & 0.0000918 & 0.11 \\
\hline TERT & 106.5577 & 14.31815 & -0.0003318 & -0.65 & -0.0001709 & -0.32 \\
\hline$M A R$ & 26.91286 & 1.422508 & -0.0069107 & -1.08 & -0.0069776 & -1.12 \\
\hline$D I V$ & 1.9587 & 0.75736 & 0.0212492 & 1.49 & 0.0173886 & 1.23 \\
\hline$U N E M P$ & 8.321731 & 4.049602 & -0.0098696 & $-4.32 * * *$ & -0.0062497 & $-2.36^{* *}$ \\
\hline$C O N$ & 67.36484 & 19.78816 & -0.0020536 & $-2.08 * *$ & -0.0023009 & $-2.42 * *$ \\
\hline OUTS & 26.26104 & 14.62286 & 0.0046032 & $1.75^{*}$ & 0.0014423 & 0.46 \\
\hline PARTT & 29.69937 & 16.5699 & 0.002265 & $2.08 * *$ & 0.0012476 & 1.10 \\
\hline$S O C$ & 2.244505 & 1.096679 & 0.0900977 & $4.53 * * *$ & 0.0976812 & $4.73 * * *$ \\
\hline$M A T E R$ & 16.32418 & 1.920914 & 0.007756 & $1.87^{*}$ & 0.0053913 & 1.31 \\
\hline${ }_{-} \mathrm{CONT}$ & & & 1.357872 & $37.00 * * *$ & 1.535296 & $42.91 * * *$ \\
\hline \multicolumn{7}{|c|}{${ }^{\Psi} F$-test for joint significance } \\
\hline Fixed (country) effects & & & $F_{(12,146)}^{\Psi}$ & $7.38 * * *$ & $F_{(12,134)}^{\Psi}$ & $7.11^{* * *}$ \\
\hline Time (year) effects & & & $\mathrm{X}$ & & $F_{(12,134)}^{\Psi}$ & $2.38^{* * *}$ \\
\hline Overall $R$-square & & & 0.5413 & & 0.4313 & \\
\hline
\end{tabular}

Effective sample: 169 observations (13 countries $\times 13$ years).

***significant at 0.01

$* *$ significant at 0.05 .

*significant at 0.10 .

Variable definitions: FERTILITY: fertility rate (mean number of live children born to a woman);

$\mathrm{FEMP}=$ female labor force participation rate; TERT $=$ female tertiary education attainment rate;

$\mathrm{MAR}=$ female median age at marriage; $\mathrm{DIV}=$ proportion of divorces per year as a percentage of the total population; $\mathrm{UNEMP}=$ total unemployment rate; $\mathrm{CON}=$ contraceptive usage rate; OUTS $=$ percentage of births occurring out of wedlock; PARTT = female part-time labor participation; SOC=government spending on maternity and family-related programs as a percentage of total government expenditures; MATER = length of government-mandated maternity leave.

proportion of government spending dedicated to maternity-related social programs, the country's fertility rate is predicted to increase by 0.0900977 , and for every oneweek increase in the length on maternity leave, fertility rate is expect to increase by 0.007756. Also, our results show that the availability of part-time work has a significant positive impact on fertility rate. For every percentage point increase in the percent of working women who work part-time, fertility rate is expected to increase by 0.002265 .

Other social factors do seem to negatively contribute to countries' fertility rates. Our results predict that a percentage point increase in a country's unemployment rate will decrease its fertility rate by 0.0098696 . Similarly, a percentage point increase in the rate of contraceptive usage is predicted to decrease fertility rate by 0.0020536 .

\section{CONCLUSIONS AND POLICY IMPLICATIONS}

The results of this study suggest that although labor force participation and higher education have historically had a negative impact on fertility rate, their effects have been mitigated by governments' and firms' efforts to provide appropriate maternity leave policies and social spending and by firms' efforts to provide more flexible 
working hours to their female employees. Because the data set used spans from 1990 to 2003 , it is probable that governments and firms had already enacted sufficient maternity programs by the 1990s. The negative relationships between higher education and fertility and labor force participation and fertility found in other studies may be specific to more historical time periods used by other researchers.

If female participation and higher education do not negatively contribute to fertility decisions, what factors are driving down European fertility rates to their currently abysmal levels? The results indicate that other social factors such as unemployment rate and contraceptive use negatively contribute to fertility rate. However, it is unlikely that these two factors are the only factors that negatively contribute to fertility rate. It is conceivable that the specified econometric model suffers from omitted variable bias. ${ }^{12}$ In their 1996 study, Galor and Weil suggest that fertility decisions may be closely tied to the relative wages of females to males. That is, as females' wages increase, the cost of having children increases and fertility decreases. However, because of the lack of data associated to wages, this study does not account for this hypothesis. Additionally, due to the lack of reliable data and the fact that some factors may not be quantifiable, it was not feasible to include other variables in our model that are mentioned in literature related to this topic. Such factors may include the costs of raising children, ${ }^{13}$ changing attitudes toward childbearing, ${ }^{14}$ increased life expectancy, ${ }^{15}$ or even the proximity of grandparents and other family members. ${ }^{16}$

The results of this study have identified that part-time employment opportunities, employment rate, percentage of births that occur outside of wedlock, contraceptive usage, and age at marriage all influence fertility decisions. However, the results of this study suggest that advanced opportunities for women in education or the labor market are no longer direct negative contributors to fertility decisions. Such results suggest that governments and firms may have already successfully combated the challenges associated with childbearing. There may no longer be the need to initiate new maternity-related programs; however, current programs should be maintained, as they seem to be valuable in making maternity more manageable for working women. One more potential avenue to mitigate dwindling fertility rates could be to use a well-guided immigration policy.

\section{Acknowledgements}

We would like to thank four anonymous referees and the editor of this journal for their constructive suggestions, and Brenda Ellis for her excellent editorial comments. The usual caveat applies.

\section{Notes}

1. Bettio and Villa [1998] in their cross-country study of Mediterranean Europe conclude that the combination of low fertility and low participation is mainly due to a family-centered welfare system.

2. According to Becker [1960], parents are assumed to have preferences regarding both the number and educational level of their children, where the educational level is affected by the amount of time and other resources that parents spend on their children. Investments in children's human capital may then be derived as a function of income and prices. As wages rise, parents increase their investments in human capital, combined with a decrease in the number of children.

3. In a separate related empirical paper, Adsera [2005], relying on a sample of OECD countries, demonstrates that high unemployment could lead to lower fertility. 
4. Easterlin and Crimmins [1987] present a "supply-demand theory" that integrates economic and sociological approaches to fertility determination. Essentially as per this classic work, it is couples' motivation for fertility control that appears to be the prime factor rather than access to family planning services or unfavorable attitudes toward such services.

5. In a case study of Sweden, Hoem [1990] provided convincing evidence that a marked reduction in the length of time between successive births appears to be mainly due to financial incentives of extending paid maternity leave.

6. We employed a single equation framework by treating FEMP as a purely exogenous variable only after we failed to detect a possible simultaneity between FER and FEMP based a rigorous test. Specifically, Hausman [1978] specification test proposed by Spencer and Berk [1981] is employed. Briefly, this test entails adding the residual from a reduced form run of FEMP equation to the original FER model as an additional regressor and then testing for its statistical significance. If "significant" implies simultaneity. The " $z$ " value is 0.92 with a $P$-value $=0.358$ which is "not statistically significant" implies a lack of simultaneity betweenFER andFEMP. To conserve space full regression results of the Hausman simultaneity test are not included in the paper but can be obtained upon a request.

7. The $\chi$ 20 test statistic of 48.38 (significant at the 0.01 level) suggests that we can reject the null hypothesis that there is no significant difference between random and fixed effect estimators. Hence the fixed effects method is employed. Further, as suggested by one of the referees we augmented this specification by adding $12(=13-1)$ year dummies to capture "time-specific" effects. These results are also reported in Table 1 under "Fixed Effects Model + Time Effects." Specifically, FEMP,TERT,$M A R$, and $D I V$ are statistically insignificant under both models. Further, under the augmented model both OUTS and PARTT exhibit lack of statistical significance. Since for the most part our findings are similar under both the specifications, we focus our discussion only on the "Fixed Effects Model."

8. No previous studies that found that labor force participation and tertiary education contributed to fertility rate described correcting for autocorrelation. Before correcting our original specification for autocorrelation, both the coefficient for female labor force participation and the coefficient for female attainment of tertiary education were significant. Due to autocorrelation correction one annual observation for each country is lost, resulting in a final sample of 169 ( $=13$ countries $\times 13$ years).

9. Previous literature suggests that fertility trends may be significantly different [Del Boca 2003] between Northern European and Southern European countries. As an attempt to capture any difference in fertility patterns between Northern and Southern countries, a dummy variable $(N O R T H)$ is added to the original model, which proved to be insignificant. Hence we did not find any significant differences in fertility among Northern and Southern European countries. These results can be obtained upon request.

10. Even though we found this variable to be insignificant, Sobotka [2004] found in his study that the trend of increasing age at motherhood negatively affects fertility in Europe.

11. $\mathrm{F}(4,146)=1.06$, with a $P$-value of 0.3786 .

12. Even though we did not investigate the possible link between fertility and infant mortality, Rosenweig and Schultz [1983] allow for possible feedback between them.

13. See DiPrete et al. [2004].

14. See d'Addio and d'Ercole [2005].

15. See Falcão and Rodrigo [2006].

16. See Del Boca [2003].

\section{References}

Adsera, Alicia. 2004. Changing Fertility Rates in Developed Countries: The Impact of Labor Market Institutions. Journal of Population Economics, 17(1): 17-43.

2005. Vanishing Children: From High Unemployment to Low Fertility in Developed Countries. American Economic Review, 95(2): 189-193.

2006. An Economic Analysis of the Gap Between Desired and Actual Fertility: The Case of Spain. Review of Economics of the Household, 4(1): 75-95.

Ahn, Namkee, and Pedro Mira. 2002. A Note on the Changing Relationship Between Fertility Rates and Female Employment Rates in Developed Countries. Journal of Population Economics, 15(4): 667-682.

Becker, Gary S. 1960. An Economic Analysis of Fertility, in Demographic and Economic Change in Developing Countries: A Conference of the Universities, Ed: National Bureau Committee for Economic Research Princeton: Princeton University Press, 209-231. 
Becker, Gary S. and H. Lewis. 1973. On the Interaction between the Quantity and Quality of Children. Journal of Political Economy, S279-S288.

Bettio, Francesca, and Paola Villa. 1998. Mediterranean Perspective on the Breakdown of the Relationship between Participation and Fertility. Cambridge Journal of Economics, 22(2): 137-171.

Butz, William P., and Michael M. Ward. 1979. The Emergence of Countercyclical U.S. Fertility. American Economic Review, 69(3): 318-328.

d'Addio, Anna C., and Marco M. d'Ercole. 2005. Trends and Determinants of Fertility in OECD Countries: The Role of Policies, OECD Social, Employment Migration Working Papers, September 2005.

Del Boca, Daniela. 2002. The Effect of Child Care and Part Time Opportunities on Participation and Fertility Decisions in Italy. Journal of Population Economics, 15: 549-573.

2003. Why are Fertility and Participation Rates so Low in Italy (and Southern Europe)?, A paper presented at the Italian Academy at Columbia University, New York, October 2003.

Del Bono, Emilia. 2002. Total Fertility Rates and Female Labour Force Participation in Great Britain and Italy, University of Oxford Working Paper, June 2002.

DiPrete, Thomas A, S. Philip Morgan, Henriette Engelhardt, and Hana Pacalova. 2004. Do CrossNational Differences in the Costs of Children Generate Cross-National Differences in Fertility Rates? Population Research and Policy Review, 22(5/6): 439-477.

Di Tommaso, Maria Laura. 1999. A Trivariate Model of Participation, Fertility and Wages. Cambridge Journal of Economics, 23(5): 623-640.

Easterlin, Richard, and Eileen Crimmins. 1987. The Fertility Revolution: A Supply-Demand Analysis. Annals of the American Academy of Political and Social Science, 491: 210-212.

Engelhardt, Henriette, Tomas Kögel, and Alexia Prskawetz. 2001. Fertility and Female Employment Reconsidered, Max-Planck-Institut für Demografische Forchung MPIDR WORKING PAPER WP 2001-021, July 2001.

Falcão, Bruno, and Soares Rodrigo. 2006. The Demographic Transition and the Sexual Division of Labor, Department of Economics PUC-Rio, Textos para discussão, Number 528, October 2006.

Galor, Oded, and David Weil. 1996. The Gender Gap, Fertility, and Growth. The American Economic Review, 86(3): 374-387.

Hausman, Jerry. 1978. Specification Tests in Econometrics. Econometrica, 46(6): 1251-1271.

Hoem, Jan M. 1990. Social Policy and Recent Fertility Change in Sweden. Population and Development Review, 16(4): 735-748.

Marston, Cicely, and John Cleland. 2003. Relationships Between Contraception and Abortion: Review of the Evidence. International Family Planning Perspective, 29(1): 6-13.

Neyer, Gerda. 2003. Family Policies and Low Fertility in Western Europe, Max-Planck-Institut für demografische Forschung MPIDR WORKING PAPER WP 2003-021, July 2003.

Righi, Alessandra. 2003. Le tendenze di fecondità e di partecipazione femminile al mercato del lavoro. Seminario Cnel-Istat 2003.

Rindfuss, Ronald, S. Philip Morgan, and Kate Offutt. 1996. Education and the Changing Age Pattern of American Fertility: 1963-1989. Demography, 33(1): 277-290.

Rønsen, Marit. 1999. Impacts on Fertility and Female Employment of Parental Leave Programs: Evidence from Three Nordic Countries, A paper presented at the European Population Conference, The Hague, Netherlands, August 1999.

Rosenweig, Mark, and Paul Schultz. 1983. Consumer Demand and Household Production: The Relationship between Fertility and Child Mortality. American Economic Review, 73(2): 38-42.

Spencer, David, and Kenneth Berk. 1981. A Limited Information Specification Test. Econometrica, 49(4): 1583-1588.

Sobotka, Tomáš. 2004. Is Lowest-Low Fertility in Europe Explained by the Postponement of Childbearing? Population and Development Review, 30: 195-220.

Willis, Robert J. 1973. A New Approach to the Economic Theory of Fertility Behavior. Journal of Political Economy, 81: 14-64. 